\title{
Human articular surface contours and related surface depression frequency studies
}

\author{
I. C. CLARKE \\ Bio Engineering Unit, University of Strathclyde, Glasgow
}

While our understanding of the composition and structure of articular cartilage has increased substantially in the last two decades, a precise description of articular surface contours has been lacking. Indeed there is not even universal agreement regarding the degree of surface roughness.

An early study of adult rabbit and dog articular cartilages by Elliott (1936) described cells frequently lying exposed on the articular surfaces and partially worn flush with the surfaces, which seemed to indicate a process of erosion. Further studies by Cameron and Robinson (1958) with newborn infant cartilage indicated that these articular surfaces also contained irregularities and protruding cells, as did the articular surfaces of mice of various ages studied by Silberberg, Silberberg, Vogel, and Wettstein (1961).

On the other hand, Davies, Barnett, Cochrane and Palfrey (1962), and Barnett, Cochrane, and Palfrey (1963) described rabbit articular surfaces as very smooth. Surface irregularities were less than $0 \cdot 2 \mu \mathrm{m}$. in young adult specimens, increasing to $0.3 \mu \mathrm{m}$. in older specimens with occasional crests $0.8 \mu \mathrm{m}$. high and fissures $1 \cdot 3 \mu \mathrm{m}$. deep. The superficial cells described in these studies were always covered by a layer of matrix with no evidence of surface depressions large enough to have contained cells.

Meachim, Ghadially, and Collins (1965) described the more irregular contours in fibrillated articular surfaces of adult human cartilage. These areas contained small pits which appeared to have been formed by the rupture or erosion of enlarged superficial lacunae.

Adult human articular surfaces described by Weiss, Rosenberg, and Helfet (1968) contained asperities of similar magnitude to those described by Davies and others (1962) and Barnett and others (1963) in rabbit articular surfaces. There was no evidence of surface erosion taking place on these surfaces.

Two types of human articular surface contours were described by McCall (1968) in a scanning electron microscope study. Immature specimens contained cell nests covered by a fine fibrillar network, whereas mature specimens had surfaces apparently composed of arrays of parallel ridges.

Walker, Dowson, Longfield, and Wright (1968) measured human articular surface contours indirectly by means of acrylic replicas. These indicated that articular surfaces were rougher than former microstudies would indicate, with humps ranging from 0.75 to $5 \mu \mathrm{m}$. in height, occurring at intervals which varied from 25 to $250 \mu \mathrm{m}$. A subsequent scanning electron microscope study (Walker, Sikorski, Dowson, Longfield, Wright and Buckley 1969) described surface ridges on human articular surfaces similar to those demonstrated by McCall (1968).

Meachim and Roy (1969), in a further study of adult human articular surfaces, described intact articular surfaces as smooth or gently undulating. In disrupted surface areas there appeared to be erosion of the cartilage accompanied by extensive loss of cartilage matrix resulting in irregular surface contours. However, they could find no evidence of cell shedding, although cells were occasionally exposed in the surface clefts.

Gardner and Woodward (1969) used light, transmission, and scanning electron microscopy to demonstrate that guinea-pig articular surfaces contained $400 \mathrm{~mm}$. diameter hollows with small 20 to $40 \mu \mathrm{m}$. diameter hollows superimposed upon them. Some surface areas contained ridges similar to those described by McCall (1968) and Walker and others (1969).

A more recent scanning electron microscope study (Clarke, 1970) demonstrated that adult human articular surfaces contained 20 to $30 \mu \mathrm{m}$. diameter hollows which were similar to these described by Gardner and Woodward (1969) in guinea-pig articular surfaces. The 20 to $30 \mu \mathrm{m}$. surface depressions were shown to correspond in shape and magnitude to the underlying superficial lacunae and it was suggested that ridges on the articular surfaces of human specimens were artefacts produced during preparation. 
In order to determine whether the regular surface depressions previously reported (Clarke, 1970) were themselves dehydration artefacts, a study of intact undehydrated specimens was made using direct and indirect methods.

The articular surfaces of these specimens were studied by reflected light and replicas taken from the surfaces were studied by scanning electron microscopy.

To investigate the suggested relationship between the surface depressions and underlying lacunae (Clarke, 1970), the replica and reflected-light studies were co-ordinated with transmitted-light and scanning electron microscope studies. From these, the number of lacunae and surface depressions per unit area visible on sectioned and articular surfaces respectively were estimated and compared.

\section{Material and methods}

Human femoral heads obtained post mortem were generally fixed in 10 per cent. buffered formol saline solution for periods of 1 to 4 weeks unless required for reflectedlight or surface replication studies, in which case they were immersed in Ringer's solution after the autopsy and studied within a few hours.

The results were generally based on specimens varying from 32 to 67 years of age and the numerical results were taken from six femoral specimens ranging from $\mathbf{4 3}$ to 76 years of age. The areas examined on the superior aspects of these specimens were limited to those which were either smooth or had a limited amount of superficial fibrillation, classed as grades 0 to 1 by Collins (1949). Grossly fibrillated areas were ignored for the purposes of this study.

\section{REFLECTED-LIGHT STUDIES}

Intact unfixed femoral heads were examined immediately on removal from Ringer's solution so that effects of surface-drying could be studied.

The formalin-fixed material was first sawn into blocks measuring $2 \times 1 \times 1 \mathrm{~cm}$. and then frozen to $-150^{\circ} \mathrm{C}$. in a vacuum flask containing Arcton 12 refrigerant. These were then mounted in a Leitz sledge microtome set to cut at $10 \mu \mathrm{m}$. and a tangential slice was removed from selected areas on the articular surface.

These specimens were studied in a standard Vickers reflected-light microscope and a Vickers ' 55 ' reflectedlight microscope.

\section{TRANSMITTED-LIGHT STUDIES}

The tangential slices removed from the above specimens were stained in celestin blue for $10 \mathrm{~min}$. and then in Mayer's haematoxylin for $10 \mathrm{~min}$., washing after each stain.

They were then blued in Scott's tap-water substitute and rewashed, further stained with Van Geison reagents for 5 min., dehydrated, cleared, and mounted.

The nuclei appeared blue-black, the collagen red, and the background yellow. The sections were studied in Leitz Ortholux and Nikon Wild microscopes.

SCANNING ELECTRON MICROSCOPE STUDIES The specimens initially studied by reflected light were dehydrated in ascending strengths of acetone after fixa- tion in 10 per cent. buffered formol saline solution.

They were then cut or fractured as required and mounted on stubs using Evostik. The stubs were left overnight in a desiccator containing phosphorous pentoxide and again overnight under a vacuum of $10^{-4} \mathrm{~mm}$. $\mathrm{Hg}$ to ensure complete dehydration. The dried specimens were coated with gold palladium (60/40) wire, $15 \times 0.4$ $\mathrm{mm}$., extra coats sometimes being required for very large specimens.

The specimens were examined in a Stereoscan IIA scanning electron microscope at a gun voltage of $10 \mathrm{kV}$ to minimize the risk of beam damage.

SURFACE REPLICA STUDIES

Two casting media were used: 'Acrulite' (an Acrylic resin) and Araldite (resin AV100 hardener HV100). The $8 \mathrm{~mm}$. diameter casts were made both on visibly moist surfaces and on those which had been wiped dry or allowed to air-dry.

The specimens were generally kept almost completely immersed in Ringer's solution to minimize further dehydration while the replica material set, which was approximately $10 \mathrm{~min}$. for the Acrulite and $24 \mathrm{hrs}$ for the Araldite.

The Araldite replicas generally had to be torn off the articular surfaces and then required maceration in caustic solution to remove attached cartilage matrix.

To determine the replication qualities and natural surface characteristics of the casting media, control samples were cast on polished glass slides and also on microscope specimen stubs to provide a natural surface. The slides had been rinsed in acetone and polished with a lens tissue and appeared featureless at magnifications up tp 20,000. The replicas were then mounted and coated as detailed in the scanning electron microscope section.

\section{Lacuna and Depression Counts}

The lacunae and surface depressions were photographed and counted, allowance being made of the angle of specimen tilt in the case of the scanning electron micrographs. In addition, the histological sections were studied in a 'Leitz Ortholux' projection microscope for further frequency calculations.

The maximum and minimum diameters, as measured along the major axes of the elliptical shaped contours, were calculated from each area studied.

For the purposes of this study, the 20 to $50 \mu \mathrm{m}$. diameter lacunae were counted rather than the nuclei lying inside, as this was not intended to be a nuclear count but rather a comparison between surface depressions and underlying lacunar frequencies. The lacuna counts per unit area in the histological sections can be only an approximation because each section has a finite thickness and this thickness will also vary from section to section. Similarly, lacuna counts per unit volume are again only approximate because of the varying thicknesses of each section. However, the calculations were made, assuming a mean section thickness, in order to have a comparison with published data on nuclear counts from radial sections.

\section{Results}

REFLECTED-LIGHT STUDIES

The surfaces of the moist femoral heads that had been immersed in Ringer's solution revealed a 
variety of contours which appeared to be due to a film of fluid adhering to the articular surfaces.

When first examined, the surfaces were featureless because of this film, but as the film began to disperse the pools and tendrils of fluid created many types of 'contours' (Fig. 1). Once this film had either dispersed completely or been wiped off with a tissue, the underlying articular surface contours became visible (Fig. 2).

The surface appearance varied considerably from area to area and from specimen to specimen. This may have been due to varying degrees of surface fibrillation but the available resolution did not enable this to be confirmed satisfactorily by this technique. Oval-shaped contours were visible on these surfaces and tended to occur in pairs, which gave them a 'figure of eight' appearance (Fig. 2).

Specimens stored in formol saline and also those stored at $-29^{\circ} \mathrm{C}$. (Fig. 3) contained contours similar to those described in the above 'fresh' material.
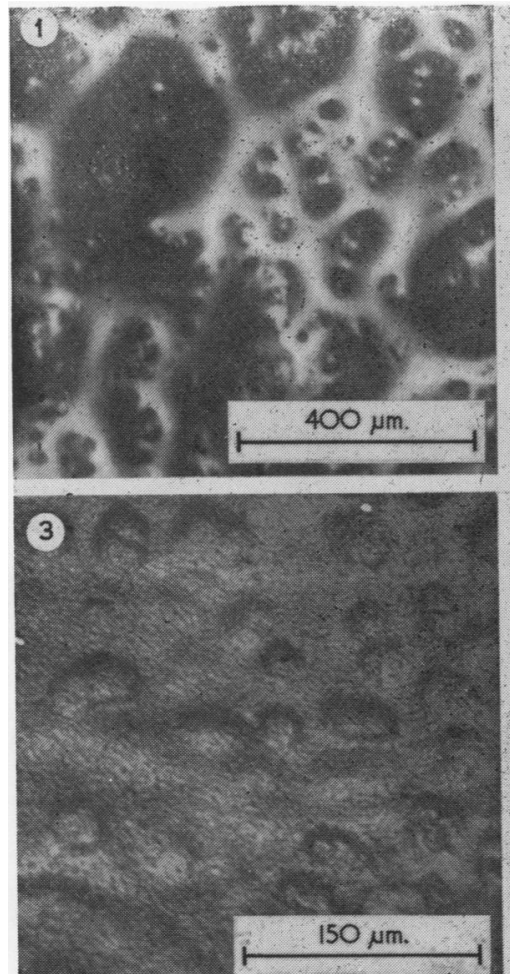

FIG. 1 Reflected-light micrograph illustrating varlety of contours seen on moist articular surfaces (specimen 43 years of age) a few minutes after removal from Ringer's solution. The film of fluid on the surface has only partially dispersed.

FIG. 3 Reflected-light micrograph, showing 'figure-ofeight' surface depressions of a specimen ( 72 years of age) which had been stored at $-29^{\circ} \mathrm{C}$. for several months.
An average frequency of $244 / \mathrm{mm}^{2}$ was obtained for these contours (Table I, overleaf) and the ovals averaged 18 to $39 \mu \mathrm{m}$. in diameter.

Formalin-fixed specimens which had tangential slices removed from selected areas exhibited similar contours on both cut and intact articular surfaces (Fig. 4). The contours on the sectioned surfaces averaged 25 to $47 \mu \mathrm{m}$. in diameter and had an average frequency of $284 / \mathrm{mm}^{2}$ (Table I). These contours on the sectioned surfaces were generally better defined than those on the articular surfaces, which may account for the higher average.

\section{TRANSMITTED-LIGHT STUDIES}

A few of the tangential sections studied contained no cellular structures at all. These presumably had been cut from the acellular surface zone.

However, the sections generally contained numerous lacunar structures which exhibited from one to six nuclei, depending on the section. The lacunae nearest the edges of the sections, which corresponded

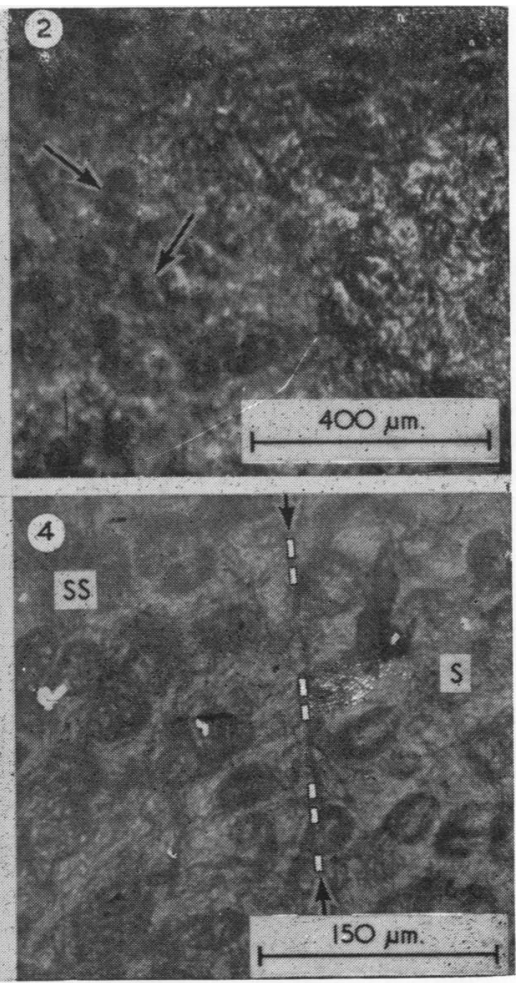

FIG. 2 Reflected-light micrograph of articular surface which was visible once the fluid film had completely dispersed (specimen 43 years of age). 'Figure-of-eight' contours (arrowed) are visible in the irregular and perhaps fibrillated surface.

FIG. 4 Reflected-light micrograph of lacunae exposed on the tangentially sectioned surface (SS) of a specimen (43 years of age). Similar shaped depressions are evident on the intact articular surface $(S)$. 
Table I Magnitude and frequency of depressions and lacunae: obtained from light and electron microscope studies

\begin{tabular}{|c|c|c|c|c|c|c|}
\hline \multirow[t]{2}{*}{ Study } & \multirow[t]{2}{*}{$\begin{array}{l}\text { Area } \\
\text { studied }\end{array}$} & \multirow[t]{2}{*}{$\begin{array}{l}\text { No. of } \\
\text { areas }\end{array}$} & \multicolumn{2}{|c|}{$\begin{array}{l}\text { Diameter of lacunae or } \\
\text { depressions }\end{array}$} & \multicolumn{2}{|c|}{$\begin{array}{l}\text { Frequency of lacunae or } \\
\text { depressions }\end{array}$} \\
\hline & & & $\begin{array}{l}\text { Range } \\
(\mu \mathrm{m} .)\end{array}$ & $\begin{array}{l}\text { Average } \\
(\mu \mathrm{m} .)\end{array}$ & $\begin{array}{l}\text { Range } \\
\text { (per mm.2) }\end{array}$ & $\begin{array}{l}\text { Average } \\
\left.\text { (per mm. } .^{2}\right)\end{array}$ \\
\hline \multirow{2}{*}{$\begin{array}{l}\text { Reflected } \\
\text { light }\end{array}$} & $\begin{array}{l}\text { Sectioned } \\
\text { surface }\end{array}$ & 6 & $13-58$ & $25-47$ & $191-366$ & 284 \\
\hline & $\begin{array}{l}\text { Articular } \\
\text { surface }\end{array}$ & 8 & $12-54$ & $18-39$ & $200-323$ & 244 \\
\hline $\begin{array}{l}\text { Transmitted } \\
\text { light }\end{array}$ & $\begin{array}{l}\text { Tangential } \\
\text { section }\end{array}$ & 17 & $12-61$ & $20-45$ & $237-600$ & 450 \\
\hline \multirow{4}{*}{$\begin{array}{l}\text { Scanning } \\
\text { electron } \\
\text { microscope }\end{array}$} & $\begin{array}{l}\text { Araldite } \\
\text { replica }\end{array}$ & 16 & $12-60$ & $21-38$ & $153-700$ & 341 \\
\hline & $\begin{array}{l}\text { Acrulite } \\
\text { replica }\end{array}$ & 12 & $6-60$ & $11-40$ & $1,040-2,530$ & 1,385 \\
\hline & $\begin{array}{l}\text { Sectioned } \\
\text { surface }\end{array}$ & 19 & $10-48$ & $17-30$ & $185-890$ & 560 \\
\hline & $\begin{array}{l}\text { Articular } \\
\text { surface }\end{array}$ & 21 & $7-68$ & $20-35$ & $190-837$ & 470 \\
\hline \multicolumn{3}{|c|}{ f diameters and frequency } & & $20-38$ & & 430 \\
\hline
\end{tabular}

*The Acrulite replica data was excluded from the overall average figures.

to the thinnest and most superficial part of the tangential slices were frequently empty (Fig. 5), but this could be due to a loss of cellular material on sectioning.

In the central areas of these sections, both empty lacunae and lacunae filled with nuclei were evident (Fig. 6). There was considerable variation in the shape of the lacunae but the compact and elongated 'figures of eight' described by Clarke (1970) were again evident. The lacunar ovals averaged 20 to $45 \mu \mathrm{m}$. in diameter with an average frequency of $450 / \mathrm{mm}^{2}$

Assuming a mean value of section thickness $(10 \mu \mathrm{m}$.) a frequency range of 23,700 to 60,000 lacunae/ $\mathrm{mm}^{3}$ was obtained. This was compared with the available data on nuclear counts $/ \mathrm{mm}^{.}{ }^{3}$ in Table II.

\section{SURFACE REPLICA STUDIES}

The control replicas from the glass surfaces were satisfactorily smooth for both materials at magnifications up to $\times 5,000$. The natural surfaces of the Araldite control specimens were also satisfactorily smooth at magnifications up to $\times 1,000$, whereas the Acrulite natural surfaces exhibited arrays of rounded protuberances at $\times 25$ magnifications and above.

From articular surfaces the Araldite replicas contained arrays of 'humps' (Fig. 7), apparently corresponding to the articular surface depressions although the 'figure of eight' contours were not at all well defined. There did not appear to be any significant difference between the replicas cast on moist surfaces and those cast on surfaces which had partially dried out. Some replicas, however, con-

Table II Comparison of frequency of lacunae obtained from tangential surface sections with published data of nuclear frequency in radial sections in adult human specimens

\begin{tabular}{|c|c|c|c|}
\hline Report & Material & Section & Cell frequency/mm. \\
\hline Meachim and Collins (1962) & Upper end of humerus & $\begin{array}{l}\text { Radial } \\
.22 \mathrm{~mm} \text {. deep }\end{array}$ & $43,500-61,800$ \\
\hline Stockwell (1967) & Lower end of femur & $\begin{array}{l}\text { Radial } \\
.22 \mathrm{~mm} \text {. deep }\end{array}$ & $\begin{array}{l}37,000-97,000 \\
(62,000 \text { average })\end{array}$ \\
\hline Stockwell (1970) & Lower end of femur & $\begin{array}{l}\text { Radial } \\
\cdot 12 \mathrm{~mm} \text {. deep }\end{array}$ & 67,000 \\
\hline Present study & Upper end of femur & $\begin{array}{l}\text { Tangential } \\
10 \mu \mathrm{m} \text {. deep }\end{array}$ & $23,700-60,000$ \\
\hline
\end{tabular}



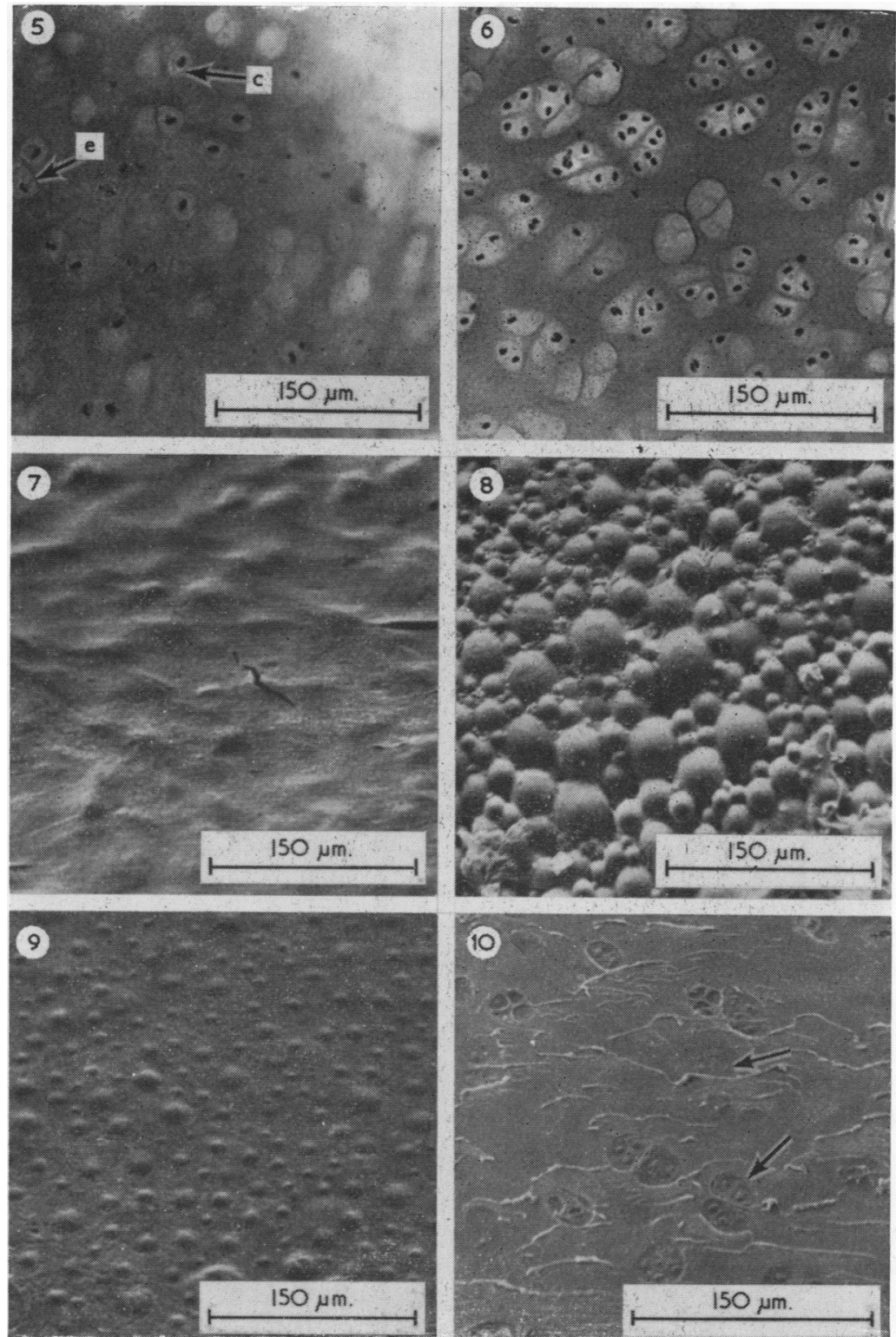

FIG. 5 Transmitted light-micrograph, showing the empty and chondrocyte-occupied lacunae at the periphery of a tangential section (specimen 32 years of age). The compact and elongated contours described earlier (Clarke, 1970) were evident in these lacunae outlines.

$c=$ compact figure of eight

$e=$ elongated figure of eight

FIG. 7 Scanning electron micrograph showing the 20 to $40 \mu \mathrm{m}$. diameter humps visible on the Araldite replica surface taken from an articular surface (specimen 43 years of age). Small cracks are also evident in the replica surface. FIG. 9 Scanning electron micrograph of an Acrulite replica (43-year-old specimen), showing the regular array of 6 to $20 \mu \mathrm{m}$. diameter hillocks on the surface.

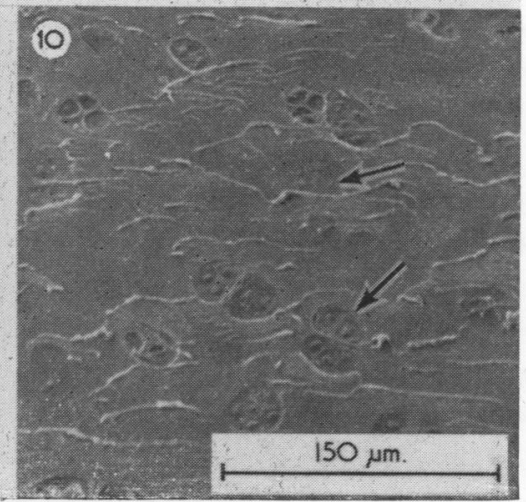

FIG. 6 Transmitted-light micrograph, showing clusters of empty and chondrocyte-occupied lacunae in the central region of a tangential section (specimen 64 years of age). The figure-of-eight lacunae outlines are evident, some containing from one to four nuclei.

FIG. 8 Scanning electron micrograph of an Acrulite replica from an articular surface (specimen 43 years of age). The regular $40 \mu \mathrm{m}$. diameter humps are interspersed by smaller humps, 10 to $20 \mu \mathrm{m}$. in diameter.

FIG. 10 Scanning electron micrograph of a sectioned surface (specimen 43 years of age), showing the typical figure-of-eight shaped lacunae. Small round protuberances are evident in the lacunae and the adjacent matrix (arrowed) which appear to correspond to the nuclei visible in the lacunae of Figs 5 and 6. 
tained large fissures and other irregularities which bore no relation to the corresponding articular surfaces.

The 'humps' on the Araldite replicas averaged 21 to $38 \mu \mathrm{m}$. in diameter with an average frequency of $341 / \mathrm{mm} .^{2}$ (Table I). This was comparable with the lacunar and depression frequencies obtained by light microscopy.

The Acrulite replicas from articular surfaces contained numerous rounded protuberances similar to those visible on the free surfaces of the Acrulite control specimens. Two distinct size ranges were evident; the layer 30 to $60 \mu \mathrm{m}$, diameter protuberances (Fig. 8) were conspicuous at the periphery of the replicas but were also intermingled with 6 to $20 \mu \mathrm{m}$. diameter protuberances (Fig. 9) in the central regions.

Taken together, the two size ranges of protuberances averaged 11 to $40 \mu \mathrm{m}$. in diameter with an average frequency of $1,385 / \mathrm{mm} .{ }^{2}$. These did not conform to the range of values obtained by the light microscopy studies and the Araldite replica study (Table I) and were omitted from the remainder of the calculations.

SCANNING ELECTRON MICROSCOPE STUDIES The surface contours described by reflected-light studies were clearly defined by the electron microscope. The sectioned areas appeared afibrous, which was perhaps due to the smearing of fibres and extrafibrillar matrix by the microtome blade (Fig. 10). Evidence of knife chatter was visible as small irregular ridges on the cut surfaces.

The 'figure of eight' shaped lacunae were again evident with many lacunae apparently filled by cellular material. Small protuberances from one to five in number were evident in some lacunae. There was a striking similarity between these and the lacunar nuclei visible by transmitted light (Figs 5 and 6). The lacunae averaged 17 to $30 \mu \mathrm{m}$. in diameter with an average frequency of $560 / \mathrm{mm}^{2}$ (Table I).

The corresponding articular surfaces contained similar shaped depressions (Fig. 11), which were generally featureless but varied a great deal in depth from specimen to specimen.

Some areas contained quite shallow depressions with protuberances (Figs 11 and 12) which appeared to correspond to those seen on the sectioned lacunae (Fig. 10) and the nuclei in the histological sections (Figs 5 and 6).

The surface layer which overlaid thcse cellular structures had a random network appearance composed of strands 50 to $100 \mu \mathrm{m}$. in thickness (Fig. 13). This network was found, with little variation, on the intact surfaces of specimens ranging from 32 to 74 years of age.

In some areas this layer had apparently ruptured over the sites of the underlying cellular structures (Evans and Clarke, 1970), but this was very rare.

In fibrillated areas the surface network became disorganized, breaking into layers with many fine tufts of matrix extending from the surface (Fig. 14). Areas fibrillated to a greater extent exhibited larger tufts of matrix in a more disorganized network, (Fig. 15). The depressions were less evident in mildly fibrillated areas and not evident at all in the badly fibrillated surfaces (Figs 14 and 15).

The depressions on the intact articular surfaces averaged 20 to $35 \mu \mathrm{m}$. in diameter with an average frequency of $470 / \mathrm{mm} .^{2}$ (Table 1 ).

Reflected-light studies demonstrated that $20-40 \mu \mathrm{m}$. surface depressions existed in intact undehydrated articular surfaces and were therefore not dehydration artefacts produced by preparation techniques. However, dehydration artefacts were encountered. Most prepared articular surfaces appeared fairly smooth to the naked eye but some specimens exhibited large irregularities after dehydration. These had a network-type of appearance and were easily recognized by the scale of such contours (Fig. 16).

\section{Discussion}

The lacuna and depression counts varied from 190 to $890 / \mathrm{mm}^{2}$ (Table I) depending on the method used, with the exception of the Acrulite replicas which varied from 1,040 to $2,530 / \mathrm{mm}^{2}$. Similar contours were found on the surfaces of Acrulite specimens which had not been in contact with articular surfaces, and since these could not therefore be representative of articular surfaces the Acrulite data was excluded from the results.

An average frequency of $430 / \mathrm{mm}^{2}$ was obtained from the remaining studies with a corresponding diameter range of 20 to $38 \mu \mathrm{m}$.

In the reflected-light studies, comparable results were obtained for the lacunar and depression frequencies in the sectioned and articular surfaces respectively. However the average frequencies from this study were lower than those from either the transmitted light or scanning electron microscope studies. This may be due to the comparatively poor resolution generally obtainable with this method and the relatively poor definition of lacunae and depressions on the moist surfaces.

Transmitted-light studies of lacunar frequency gave an average figure of $450 / \mathrm{mm} .^{2}$ This figure may be on the high side because the lacunae were counted in sections which extended from the surface to a depth of approximately $10 \mu \mathrm{m}$., whereas the data from the other studies was calculated from the surfaces only.

The estimated lacunar frequency per $\mathrm{mm} .^{3}$ fell within the range of available nuclear frequency data from the superficial zone (Table II). Thus, although 

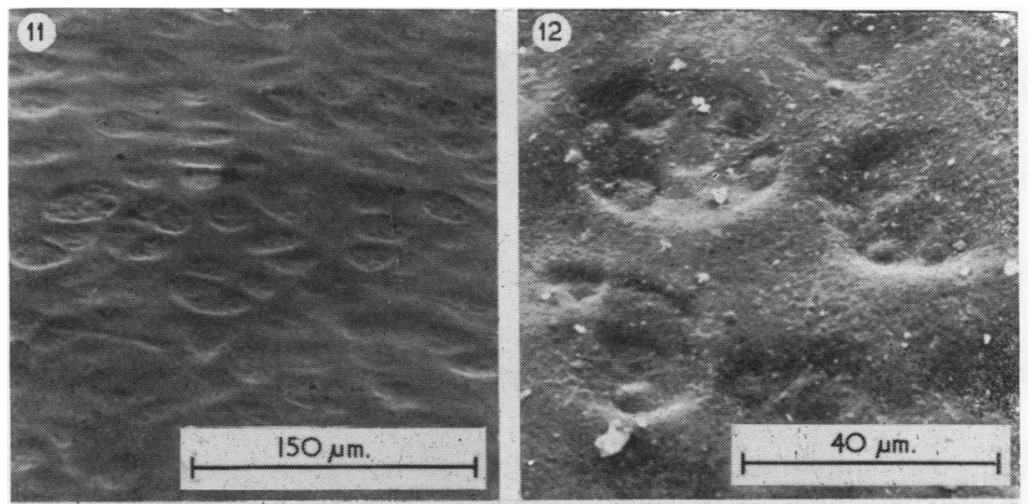

FIG. 11 Scanning electron micrograpn showing figure-ofeight shaped depressions on the articular surface (specimen 72 years of age). These depressions appear quite shallow and some contain small protuberances similar to those in Fig. 10 and also apparently corresponding to the nuclei in Figs 5 and 6.

FIG. 13 Higher magnification of a figure-of-eight depression showing no protuberances (specimen 43 years $o$ age). The surface layer has the appearance $o$ a random fibrillar network.

FIG. 15 Disrupted surface layer on the fibrillated articular surface (specimen 55 years of age). Tufts of the surface layer have become detached and the surface depressions are no longer visible.
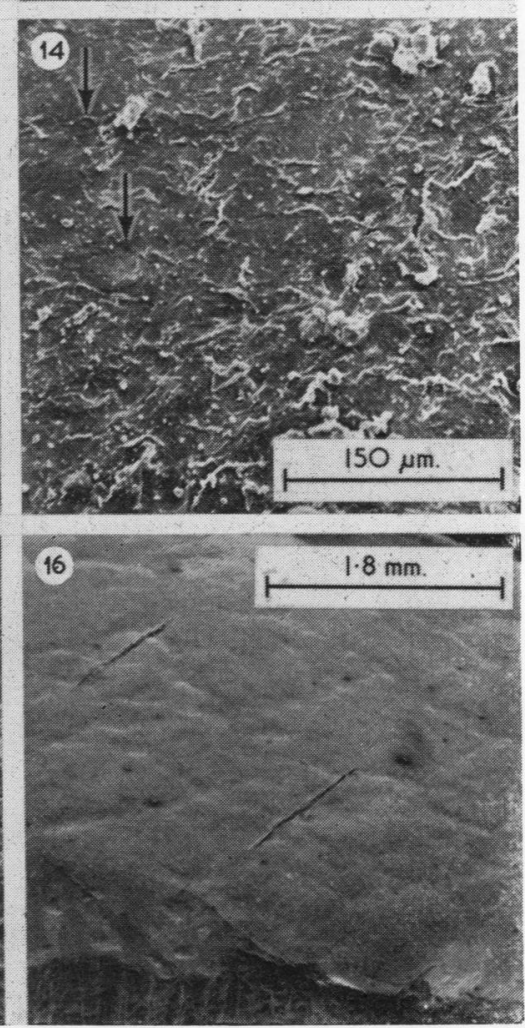

FIG. 12 Shallow depressions on the articular surface (specimen 43 years of age). Each shallow depression contains three to five small round protuberances, indicating perhaps the presence of underlying cells similar to those described in Figs 5 and 6.

FIG. 14 Mild degree of fibrillation on the articular surface (specimen 76 years of age). The surface depressions are poorly defined (arrowed) perhaps because the surface layer is becoming more irregular.

FIG. 16 General view of the articular surface and edge (specimen 55 years of age). The apparent surface collapse on dehydration has resulted in the formation of large surface irregularities. The surface also contains two splits, perhaps made by a scalpel blade during preparation. The 20 to $40 \mu \mathrm{m}$. diameter surface depressions are not visible at this low level of magnification. 
these nuclear studies may have counted several nuclei within each lacunae on occasion, the fact that empty or necrotic cellular structures were not counted (Meachim, 1970) may have had a cancelling effect and made the lacunar and nuclear frequency data comparable.

A further factor which has to be considered is the depth of section measured from the articular surface because the cellular density apparently increases as the articular surface is approached (Stockwell, 1970) (Table II).

The scanning electron microscope frequency data was again comparable for both lacunae and depressions on the sectioned and articular surfaces respectively, although the average frequencies were higher than similar data obtained by reflected-light studies (Table I). They did, however, compare with the transmitted-light data, although as previously indicated this figure may be on the high side.

The Araldite replica study produced an average frequency of $341 / \mathrm{mm}^{2}$ which lay between the reflected-light and electron microscope findings of surface depression frequency. The magnitude of the humps on the Araldite replicas also compared favourably with the surface depression magnitudes (Table I) and suggested that the Araldite replicas had followed the contours of the undehydrated surfaces although they had not reproduced the 'figure of eight' configurations with any great accuracy.

In the above studies, the depressions and lacunae exhibited similar variations in shape and magnitude (Table I). The average diameter range for these figures varied from 20 to $38 \mu \mathrm{m}$.

This correlation in shape, magnitude, and frequency between the surface depressions and the underlying lacunae suggested that the former owed their existence to the presence of the latter.

This relationship has been supported indirectly by other investigators (Meachim, 1970; Stockwell, 1970).

Earlier light and transmission electron microscope studies of radial sections of cartilage (Davies and others, 1962; Weiss and others, 1968; Meachim and Roy, 1969; Palfrey, 1970), have indicated that articular surfaces are remarkably smooth with little evidence of the depressions demonstrated by the scanning electron microscope (Gardner and Woodward, 1969; Clarke, 1970).

It would therefore seem likely, on the basis of the above microstudies, that the depressions demonstrated by the scanning electron microscope were artefacts, perhaps produced by dehydration of the tissue and subsequent surface distortion. However, the appearance of similar depressions in reflectedlight studies of intact undehydrated articular surfaces clearly demonstrates that they are not.

The depressions were apparently formed by a surface layer which closely followed the contours of the underlying lacunar structures. This layer had the appearance of a random network and could correspond to the membrane structure described by Meachim and Roy (1969) or more likely the dense network of randomly oriented fibres described by Weiss and others (1968) at the articular surface. This layer was typical of all intact surface areas examined regardless of age. However, in fibrillated areas, it became disrupted and irregular, forming the long narrow strands and shorter tufts described by Meachim and others (1965).

As was noted previously (Davies and others, 1962; Weiss and others, 1968; Meachim and Roy, 1969), there was no evidence of cell shedding from the intact surfaces in this study although areas have been found where this may have occurred (Evans and Clarke, 1970). The cellular structures were always covered by the surface layer described above and although this became disrupted in the Grade 1 fibrillated areas studied the degree of disruption in the areas studied was evidently not sufficient to expose the superficial lacunae.

Some intact surface areas contained depressions with small round protuberances which corresponded to those seen on sectioned lacunae and the nuclei visible in the sections studied by transmitted light. On this basis it is suggested that the superficial lacunae may contain cellular material or extrafibrillar material in vivo which may support the surface layer, even perhaps swelling into the joint cavity. Ekholm and Norbäck (1951) have demonstrated that cells in the superficial zone became swollen as a result of joint movement and then returned to a flattened condition after rest. It is interesting to speculate what effect this would have on the surface contours of articular cartilage. Are the cells capable of creating hillocks on the articular surfaces when they are swollen and depressions when they return to their flattened state?

\section{Summary}

The superior aspects of adult femoral heads were studied by scanning electron microscopy and transmitted- and reflected-light microscopy.

Reflected light studies of in vitro articular surfaces and scanning electron microscope studies of surface replicas indicated that intact undehydrated articular surfaces contained 12 to $60 \mu \mathrm{m}$. diameter depressions similar to those seen on the articular surfaces by scanning electron microscopy.

An overall average frequency of $430 / \mathrm{mm}^{2}$ was obtained from the studies of lacunae and surface depressions which averaged 20 to $40 \mu \mathrm{m}$. in diameter.

The depressions were evident on all intact surfaces examined but were apparently obscured in fibrillated areas. The onset of fibrillation appeared to be marked 
by the splitting of the surface layer with fine tendrils separating from the articular surface. There was no evidence of cell shedding from either the intact articular surfaces or the Grade 1 fibrillated surfaces examined.

Whether or not the surface depressions exist in vivo, there is evidence that they are produced by the lacunae underlying the surface as the surface layer follows the lacunar outlines.
This work was supported by a Science Research Council Grant No. B/SR/4322 and was carried out in the Bio Engineering Unit at the University of Strathclyde (Director, Prof. R. M. Kenedi) under the supervision of Dr. P. F. Millington.

The author is indebted to Dr. MacLeod (Metallurgy Department) for the use of laboratory facilities, to Mr. A. Robertson for help with histological techniques, and to Mr. A. McIllroy for his technical assistance with the transmitted-light micrographs.

\section{References}

Barnett, C. H., Cochrane, W., And Palfrey, A. J. (1963) Ann. rheum. Dis., 22, 389 (Age changes in the articular cartilage of rabbits).

CAmeron, D. A., AND Robinson, R. A. (1958) J. Bone Jt Surg., 40A, 163 (Electron microscopy of epiphyseal and articular cartilage matrix in the femur of newborn infant).

Clarke, I. C. (1970) J. Anat. (Lond.), (in press) (Surface characteristics of human articular cartilage-a scanning electron microscope study).

Collins, D. H. (1949) 'The Pathology of Articular and Spinal Diseases', Arnold, London.

Davies, D. V., Barnett, C. H., Cochrane, W., and Palfrey, A. J. (1962) Ann. rheum. Dis., 21, 11 (Electron microscopy of articular cartilage in the young adult rabbit).

EкHOLM, R., AND NORBÄCK, B. (1951) Acta orthop. scand., 21, 81 (On the relationship between articular changes and function).

Ellott, H. C. (1936) Amer. J. Anat., 58, 127 (Studies on articular cartilage).

Evans, J. H., AND Clarke, I. C. (1970) 'Conference of Rheology in Medicine and Pharmacy, April, 1970'. In press (Some mechanical and structural characteristics of connective tissues).

Gardner, D. L., AND Woodward, D. H. (1969) Ann. rheum. Dis., 28, 379 (Scanning electron microscopy and replica studies of articular surfaces of guinea pig synovial joints).

McCALL, J. G. (1968) Lancet, 2, 1194 (Scanning electron microscopy of articular surfaces).

MeAChim, G. (1970) Personal communication.

- AND Collins, D. H. (1962) Ann. rheum. Dis., 21, 45 (Cell counts of normal and osteo-arthritic articular cartilage in relation to the uptake of sulphate $\left({ }^{35} \mathrm{SO}^{4}\right)$ in vitro).

-, Ghadially, F. N., ANd Collins, D. H. (1965) Ibid., 24, 23 (Regressive changes in the superficial layer of human articular cartilage).

- AND Roy, S. (1969) J. Bone Jt Surg., 51B, 529 (Surface ultrastructure of mature adult human articular cartilage).

Palfrey, A. J. (1970) Contribution to Evans and Clarke (1970).

Silberberg, R., Silberberg, M., Vogel, A., AND Wettstein, W. (1961) Amer. J. Anat., 109, 251 (Ultrastructure of articular cartilage of mice of various ages).

Stockwell, R. A. (1967) J. Anat. (Lond.), 101, 753 (Cell densities of human articular and costal cartilage). (1970) Personal communication.

Walker, P. S., Dowson, D., Longfield, M. D., ANd Wright, V. (1968) Ann. rheum. Dis., 27, 512 (Boosted lubrication in synovial joints by fluid entrapment and enrichment).

-, Sikorski, J., Dowson, D., Longfield, M. D., Wright, V., AND Buckley, T. (1969) Ibid., 28,1 (Behaviour of synovial fluid on surfaces of articular cartilage).

Weiss, C., Rosenberg, L., AND Helfet, A. J. (1968) J. Bone Jt Surg., 50A, 633 (An ultrastructural study of normal young adult human articular cartilage). 